\title{
O PERFIL DA EDUCAÇÃO INFANTIL DA JURISDIÇÃO DO NÚCLEO REGIONAL DE LONDRINA
}

\author{
THE CHILD EDUCATION PROFILE OF THE JURISDICTION OF THE REGIONAL \\ NUCLEUS OF LONDRINA
}

\author{
Cristiane dos Santos Farias \\ Mestra em Educação \\ Universidade Estadual de Londrina - UEL. \\ Londrina, Paraná - Brasil. \\ crisfarias@uel.br \\ iDaria José Ferreira Ruiz \\ Pós-doutora em Educação \\ Universidade Estadual de Londrina - UEL. \\ Londrina, Paraná - Brasil \\ mjfruiz@gmail.com
}

\begin{abstract}
Resumo: O objetivo deste estudo é mapear algumas características do atendimento da Educação Infantil (EI) na jurisdição do Núcleo Regional de Educação de Londrina (NRE) compreendendo seus 19 municípios circunvizinhos. O artigo resulta da compilação de dissertação de Mestrado em Educação, realizado na Universidade Estadual de Londrina (UEL), finalizado em 2018. A questão norteadora foi saber se o atendimento deste recorte geográfico da EI tem se concentrado mais na esfera pública municipal ou nas Parcerias Público Privadas (PPPs) filantrópicas, entre outras questões relevantes. A fundamentação teórica teve aporte na Teoria do Materialismo Histórico Dialético, sendo que a abordagem metodológica utilizou pesquisa qualitativa e quantitativa, de teor bibliográfico, documental e de campo. Como instrumento de coleta de dados, foi utilizado formulário eletrônico para o mapeamento e em seguida o tratamento dos dados. O resultado indicou que as Parcerias Público Privadas - filantrópicas da EI, têm sido superadas, pois, dos 19 municípios investigados, 11 deles já não atendem por este recurso público/privado, e sim por via pública-municipal. Averiguamos ainda que a falta de vagas gera medidas que não cumprem o direito da criança em ter vaga tal qual a legislação prevê. A primeira luta ainda não foi vencida, as vagas continuam sendo disputadas pela sociedade, que não têm seus direitos garantidos na universalização da Educação Básica, principalmente para crianças de 0 a 3 anos.
\end{abstract}

Palavras-chave: direito da criança; educação infantil; parceria público privada; política educacional.

\begin{abstract}
The objective was to map some characteristics of the Infant Education (EI) in the jurisdiction of the Regional Nucleus of Education of Londrina (NRE) comprising its 19 surrounding municipalities. The article is the result of the compilation of the Master's dissertation in Education, held at the State University of Londrina (UEL), completed in 2018. The guiding question was whether the service of this geographic cut of the IE has been concentrated more in the municipal public sphere or in the Public Private Partnerships (PPPs), among other relevant issues. The theoretical basis was supported by the Theory of Dialectical Historical Materialism, and the methodological approach used qualitative and quantitative research, with a bibliographical, documentary and field content, whereby the electronic form was mapped and then processed. The result indicated that Public Private Partnerships - philanthropic of EI, has been overcome, because of the 19 municipalities investigated, 11 of them no longer care for this public / private resource, but municipal public road. We also find that the lack of vacancies creates measures that do not fulfill the right of the child to have a vacancy as the legislation provides. The first fight has not yet expired, the vacancies continue to be disputed by society, which does not have its rights guaranteed in the universalization of Basic Education, especially for children from 0 to 3 years.
\end{abstract}

Keywords: right of the child; child education; public-private partnership; educational politics.

Para citar - (ABNT NBR 6023:2018)

FARIAS, Cristiane dos Santos; RUIZ, Maria José Ferreira. O perfil da educação infantil da jurisdição do núcleo regional de Londrina. Eccos - Revista Científica, São Paulo, n. 59, p. 1-16, e13246, out./dez. 2021. Disponível em: https://doi.org/10.5585/eccos.n59.13246. 


\section{Introdução}

Necessário se faz retomar a historicidade que envolve a Educação Infantil, para então compreendermos mais especificamente o recorte geográfico desta pesquisa, que se encontra no Norte do Paraná, a fim de revelar algumas características importantes sobre o perfil da Educação Infantil e saber se o atendimento atualmente se concentra nos Centro Municipal de Educação Infantil (CMEI) ou nos Centro de Educação Infantil (CEI) filantrópicos.

Desde sua origem no Brasil, no século XVIII, a Educação Infantil é permeada pela ação da filantropia, com fortes traços de atendimento religioso. Em sua gênese, encontramos a Roda dos Excluídos, no Brasil Colônia, com intuito de educação voltado para as boas maneiras, valores e trabalho. Após esse primeiro momento, toma forma o caráter higienista, assim como o primeiro, trazido da Europa. A preocupação consistia em cuidados físicos das crianças, pois muitas crianças morriam por falta de higiene no primeiro modelo.

A criança enquanto sujeito de direito escolar decorreu de várias ações da sociedade mundial que pressionaram o Estado na responsabilização de garantir oferta da EI. No Brasil, isso aconteceu apenas com o princípio normativo da Constituição Federal (CF) (BRASIL, 1988), considerada um instrumento fundante na construção de uma EI pública, gratuita e de qualidade.

Em nosso recorte da pesquisa, o objetivo geral está em apresentar um mapeamento da jurisdição do NRE de Londrina a respeito da EI, com ênfase nas Parcerias Público/Privadas (PPPs). Para tanto, o percurso tomado levou à investigação da historicidade da EI, no que tange a suas políticas educacionais, num esforço de discutir a interferência Neoliberal nos interesses de atendimento da EI.

Com o fito de atingir tais objetivos, faremos uma discussão acerca do percurso histórico do direito da criança à educação escolar para, então, focar no recorte geográfico da pesquisa na cidade de Londrina e em sua região metropolitana do NRE da jurisdição ao revelar dados que trazem um perfil de atendimento.

\section{Breve percurso histórico do direito da criança na educação escolar}

O cuidado com as crianças abandonadas no Brasil tem marco inicial em 1828, com o assistencialismo ofertado pela Igreja Católica com as Irmãs de Caridade, no modelo trazido pela Europa chamado Roda dos Excluídos ou Roda da Misericórdia. A duração deste tipo de atendimento foi estendida até 1950 (em São Paulo e Salvador) sendo que algumas tiveram curta duração (MARCILIO, 1997). 
As crianças que eram ali deixadas refletiam diversas situações de vulnerabilidade, preconceito, miséria, casamentos ilegítimos, filhos de escravas, mães solteiras, enfim, vítimas da pobreza e da exclusão familiar e social. Neste contexto,

Até meados do século XIX, o atendimento de crianças pequenas longe da mãe em
instituições como creches ou parques infantis praticamente não existia no Brasil. No
meio rural, onde residia a maior parte da população do país na época, familiares de
fazendeiros assumiam o cuidado de crianças orfãos ou abandonadas, geralmente
frutos de exploração sexual da mulher negra e índia pelo senhor branco. Já na zona
urbana, bebês ilegítimos de moças pertencentes a famílias com prestígio social, eram
recolhidas nas "rodas dos expostos" existentes em algumas cidades desde o início do
século XVIII (OLIVEIRA, 2002, p.91).

Devido ao aumento da demanda de crianças abandonadas, as religiosas, sem ter como prover atendimento, fizeram pressão para que o Estado assumisse essa obrigação, e assim iniciou a filantropia para crianças no Brasil em 1828, quando o Estado cedeu à pressão e assentiu a responsabilidade pela "Lei dos Municípios" que estabelecia a parceria entre as Santas Casas de Misericórdia e o Estado, "perdia-se, assim, o caráter caritativo da assistência, para inaugurar-se sua fase filantrópica, associando-se o público e o particular” (MARCILIO, 1997, p. 60).

O período seguinte é comentado por Kuhlmann (2001), que atribuiu ao ingresso da mulher no mercado de trabalho a criação das primeiras creches no século XIX. É somente no término desse século que ocorre o aumento da Educação Infantil como instituição, quando as mães deixavam seus filhos aos cuidados de outros para poderem trabalhar. Porém "é a origem social e não institucional que inspirava objetivos educacionais diversos" (KUHLMANN, 2001, p.78). Ou seja, a preocupação não era a educação da criança, mas sim possibilitar que a mãe pudesse trabalhar.

Merisse (1997) explica que durante a República esse modelo permaneceu, mas com a subdivisão pré-escola para as crianças de classe média e creches assistencialistas para os pobres, sendo a maioria particulares - filantrópicas ou confessionais e ainda aquelas que atendiam nas empresas, as quais surgiram somente em 1923. As empresas foram obrigadas a instalar creches ou salas de alimentação em seu entorno para facilitar a amamentação das mães, crescendo um movimento de reinvindicação popular.

Com o cenário da Ditadura Militar, em plena industrialização no Brasil (década de 1970), esses movimentos de reivindicação por creches, mesmo que isolados, inicialmente concentrados nos estados de São Paulo e Minas Gerais, tiveram força para iniciar um grande passo que viria em seguida. Essa ação foi o germe inicial da configuração para disseminar a luta por creches, e assim aumentaram os movimentos nesse sentido. 
No final dos anos 1970 e início dos 1980, a Educação Infantil sofreu forte influência dos Organismos Internacionais, principalmente da UNICEF e da UNESCO, pois eles difundiram nos países subdesenvolvidos a prerrogativa voltada para "educação pré-escolar compensatória de carências de populações pobres e apoiadas em recursos da comunidade visando despender poucas verbas do Estado para sua expansão" (ROSEMBERG, 2002, p.33).

Esta ideia se pautava na redução de investimentos públicos, assim, a comunidade seria impelida a aderir programas de responsabilização pela Educação Infantil, com isso aumentaram o número das creches comunitárias e creches domiciliares sem nenhuma fiscalização a respeito da qualidade do atendimento.

\subsection{Quando a criança se tornou um sujeito de direito}

Para falar do Direito da criança, primeiramente é importante enfatizar o apanhado do direito desde sua origem, quando evolui do Direito Natural (o que não significa dizer que seja de fato fundamental por natureza) para o Direito Positivo, quando ganha proporção social e ramifica sua atuação para Direitos pertinentes a um determinado segmento da sociedade, já que cada fase histórica traz consigo uma especificidade própria da época, uma necessidade nova diante da sociedade constituída (BOBBIO, 2004).

Os direitos das crianças se encaixam nos sociais e por isso precisam mais do que ser declarados, precisam de muita luta para se concretizarem na prática no financiamento público como oferta de tal direito.

No início do século XX, ocorreu um grande marco internacional, em Jomtien, na Tailândia, quando aconteceu a Conferência Mundial sobre "Educação para Todos" (UNESCO, 1990) tendo como meta principal o compromisso em escala mundial de educar todos os cidadãos do planeta.

Este documento (mesmo tendo os interesses do capital como principal ideologia em demérito da condição humanitária) acabou por possibilitar um amplo debate do direito à educação da criança, assunto tratado no Art. 3, que prevê: Universalizar o acesso à educação e fomentar a equidade: “A educação básica deve ser proporcionada a todas as crianças, jovens e adultos" (UNESCO, 1990).

Esse Congresso veio logo a seguir do Consenso de Washington, realizado em 1989 nos Estados Unidos da América, com o fito econômico de inserir os países periféricos na economia de mercado. Nesta perspectiva, a educação escolar tem uma grande valia para capacitar os sujeitos sociais a dominarem os códigos da modernidade, tendo em vista o processo de 
reestruturação da produção capitalista e a globalização da economia. Este destaque é importante, uma vez que, embora existam interesses comuns em relação à democratização da educação, também existem muitas distinções na forma e no conteúdo das propostas das diferentes classes sociais para a educação pública (OLIVEIRA, 2010).

Isso materializa-se na proposição do arcabouço jurídico-legal, sendo perceptível que, em grande parte das vezes, o que consta nos marcos legais não encontram consonância com a realidade factual, ou seja, existe um ordenamento jurídico para a educação que não se executa realmente na forma proposta nestas legislações que garantem os diferentes direitos. A partir deste destaque, a seguir, uma breve explanação de como o direito à Educação Infantil vem sendo contemplado pelas normativas legais brasileiras.

\subsection{Políticas públicas para a Educação Infantil sob viés neoliberal}

No caso específico do Brasil, tomando os estudos de Cury (1998), reconhecemos que os avanços para consolidar a Educação Infantil enquanto direito da criança percorreu um longo caminho. No período anterior à Constituição de 1988, a questão da infância era responsabilidade do Amparo e da Assistência Social e não da área da Educação.

Diferentemente da origem da escola obrigatória para crianças a partir de 7 anos, a qual se apresentava pública, laica, gratuita e para todas as crianças, a Educação Infantil, antes denominada somente de creche, surgiu para atender a camada trabalhadora, principalmente das mães que entravam no mercado de trabalho. Assim, estas instituições tendiam ao cuidado, geralmente eram filantrópicas e confessionais, sendo a questão da higiene bastante enfatizada, e voltada para a criança pobre.

A superação desta marca inicial da Educação Infantil enquanto “creche assistencialista", é lenta e gradativa e ainda não foi totalmente superada no Brasil. A conscientização de que se trata de direito de todas as crianças, independentemente se a mãe trabalha ou não, se é pobre ou rica, se está na periferia ou no centro, ganha proporção a partir da Constituição, daí então a procura aumentou num ritmo acelerado, surgindo um outro problema gritante: a falta de vagas públicas, o que fez com que se mantivesse o atendimento por meio das Parcerias Público/Privadas.

Na década de 1990, os Organismos Internacionais intensificaram ações políticas, utilizando do Fundo Monetário Internacional (FMI) e do Banco Mundial (BM) que direcionaram medidas econômicas de dois eixos complementares: o da reforma educacional geral que, entre outras medidas, preconizou, em seu início, a prioridade absoluta de 
investimentos públicos no Ensino Fundamental ( já que este nível traria maior retorno ao mercado); e o da retomada da proposta de programas "não formais" a baixo investimento público de EI para crianças pequenas pobres. Com isso, o BM remeteu o atendimento da EI para o "não formal", tendo o governo como subsidiário para esse modelo (CURY, 1998).

A privatização dos serviços públicos na educação, em especial na Educação Infantil, de longa data, retira os direitos já conquistados pela população e legitima um tratamento desigual para as crianças em vários aspectos, já que cada realidade vai se deparar com disparidades de atendimento, inclusive quanto à participação na mensalidade, como no caso de alguns Centros de Educação Infantil que contam com a participação orçamentária dos pais.

Após o processo de municipalização do ensino e da ampliação das responsabilidades municipais para a Educação Infantil e o Ensino Fundamental, a Parceria Público/Privada se tonou mais procurada pelas prefeituras por serem alternativas rápidas e baratas. Na mesma proporção, ocorre "um verdadeiro processo de esvaziamento da dimensão de 'conquista' e de ‘direito' das políticas sociais" (ADRIÃO, 2009, p.168).

O fato de as filantrópicas serem "mais em conta" financeiramente para o setor público em detrimento da oferta municipal gratuita, pode ser justificado por não precisar contratar professores estatutários, assim, os salários costumam ser bem inferiores e ainda não entram na Lei de Responsabilidade Fiscal, além da questão da infraestrutura adequada (ADRIÃO, 2009).

O Plano Nacional de Educação (BRASIL, 2014) prevê universalização de atendimento para crianças de 4 e 5 anos de idade e $50 \%$ de atendimento para de 0 a 3 anos até o final da vigência do plano. Esta meta prioriza a Emenda Constitucional n.59/2009 (BRASIL, 2009) que tornou obrigatória as matrículas das crianças de 4 e 5 anos de idade na pré-escola, com prazo máximo de repasse de verbas via FUNDEB em 2016 (BRASIL, 2016a).

Devido a EC no ${ }^{\circ} 59$ da obrigatoriedade dos 4 aos 17 anos (BRASIL, 2009), houve uma inversão de ótica, o Estado, que somente deveria ofertar a vaga, passa a cobrar dos pais o dever da matrícula dessa idade, sob risco de sanções previstas no Código Penal, e assim, um direito que era subjetivo, do desejo pessoal, passa a ser direito positivo, isto é, um direito posto.

Isso traria muitas consequências para os municípios se adequarem, sendo uma delas as parcerias entre o setor público estatal e o setor privado filantrópico, fortalecendo o conveniamento. Ainda é importante destacar que a Meta 1 do PNE pode ser inviabilizada tendo em vista a promulgação, em dezembro de 2016, da Emenda Constitucional 95, que limita por 20 anos os gastos públicos (BRASIL, 2016b).

Outro fator referente à obrigatoriedade que viria a causar muitos impactos frente ao conveniamento foi a fragmentação da creche e pré-escola, pois os olhos foram voltados para o 
“obrigatório", deixando desigual o peso da oferta do município, que, então, sofreria punições frente a não oferta da pré-escola.

Garantir à criança uma educação na infância que de fato proporcione sua inserção na sociedade enquanto cidadã, que tenha suas satisfações e necessidades plenamente atendidas, não é uma conquista fácil. A força da ideologia neoliberal que assola o território educacional escolar na lógica mercadológica acarreta prejuízos ímpares para a criança no quesito do direito de ser criança, já que essa lógica faz com que o universo escolar seja antecipado na Educação Infantil.

A escola, neste cenário contemporâneo, mais parece uma empresa a serviço do mercado, seja pela competividade entre escolas por alunos-clientes, seja pela formação ideológica neoliberal que remete à meritocracia, que se valem das avaliações como recurso de recompensa ou punição, conforme denucia o autor,

[...] a transformação dos jandins de infância e escolas infantis em "pequenas empresas" prestadoras de serviços educativos e a criação de um mercado educacional para a infância, onde participam colégios que são empresas privadas e se disseminam para o interior de estabelecimentos da educação pública princípios gestionários e pedagógicos decalcados das lógicas empresariais da concorrência e da produtividade, está claramente em curso (SARMENTO, 2015, p. 77).

Este cenário é percebido por diversas faces: entre as inúmeras PPPs; nas gestões de organizações que são ditadas pelos Organismos Internacionais; na regulação utilizada pelo mercado educacional, de materiais apostilados. Desta forma, o direito da criança à Educação Infantil vem sendo desrespeitado, quando não se oferta vaga pública e gratuita, e quando se fortalece, de diferentes formas, parcerias entre o setor público e privado/filantrópico pelo conveniamento. A seguir, o recorte da jurisdição do NRE de Londrina na oferta da Educação Infantil.

\section{Mapeamento da educação infantil da jurisdição do NRE de Londrina}

A investigação foi feita por meio de formulário eletrônico do Google Forms enviado aos dezenove municípios que compõem a Jurisdição do NRE de Londrina e também por meio de pesquisas em sites oficiais. Destes dezenove municípios, doze responderam na íntegra, sendo apresentados neste artigo alguns dos indicadores levantados, são eles: Formação docente-inicial e salarial; Oferta de vagas em CMEI e CEI filantrópicas; Demanda manifesta reprimida por vagas e, finalmente, a quantidade de unidades de CMEI e de CEI. 


\subsection{A formação docente inicial no CMEI e no CEI}

Um dos gargalos mais acirrados para oferecer a EI é a contratação dos professores. Para o Estado/Município, ocorre via concurso público e testes seletivos já, para as instituições privadas, via contratação.

Questões de exigência da formação inicial para admissão docente de EI podem ser encontradas na LDB (BRASIL, 1996), contudo, antes desse marco legal regulatório, houve um período de transição da Assistência Social que não exigia formação profissional para atuar no cargo, ficando a cargo das contratações locais.

Como destaca a tabela 1, para a formação inicial do professor, há exigência de Ensino Superior para trabalhar nos CMEIs, nos municípios de Cafeara, Cambé, Centenário do Sul, Londrina e Sertanópolis, seja em licenciatura em nível superior, somada ao Magistério, seja em Pedagogia. Para os demais municípios, admitem o Magistério como forma de inclusão. Por sua vez, para atuar em CEIs, apenas Centenário do Sul e Sertanópolis exigem o Ensino Superior, todos os demais com exigência apenas do Magistério. Este dado é revelador, já que a formação docente é um indicativo de qualidade, e a maioria destes professores de nível Superior encontram-se nos CMEIs.

Tabela 1-Professores do CMEI e do CEI: perfil financeiro e formação inicial

\begin{tabular}{|c|c|c|c|c|c|c|}
\hline & \multicolumn{6}{|c|}{ DADOS DO PROFISSIONAL DA EDUCACÃO INFANTIL } \\
\hline & \multicolumn{3}{|c|}{ CMEI - Formação Inicial } & \multicolumn{3}{|c|}{ CEI - Formação Inicial } \\
\hline Municipios & 0 a 3 anos & 4 a 5 anas & Salário Inicial & O a 3 anos & 4 a 5 anas & $\begin{array}{l}\text { Salário } \\
\text { Inicial }\end{array}$ \\
\hline Alvorada Do Sul & Magistério & Magistério & $2.455,35$ & Näa se aplica & Nāa se aplica & $0, \infty 0$ \\
\hline Bela Vista Paraiso & Magistério & Magistério & $1.239,35$ & Magistério & Magistéria & $1.099,60$ \\
\hline Cafeare & Pediagagia & Pedagogia & $2.455,85$ & Näa se aplica & Nāa se aplica & $0, \infty$ \\
\hline Cambé & Pedagagia & Pedagogia & $1.541,21$ & Magistério & Magistéria & $1.100,00$ \\
\hline Cententrio Do Sul & Pedagagia & Pedagogia & $1.277,00$ & Pedagogia & Pedagogia & $1.277,00$ \\
\hline Guaraci & Magistério & Magistéria & $2.455,25$ & Näa se aplica & Nāa se aplica & $0, \infty 0$ \\
\hline Londrina & Licenciatura & Licenciatura & $2.915,85$ & Magistério & Magistério & $1.675,00$ \\
\hline Miraselva & Magistério & Magistéria & $1.789,00$ & Nảa se aplica & Nāa se aplica & 0,00 \\
\hline Pitangueiras & Magistério & Magistéria & $1.400,00$ & Nảa se aplica & Nāa se aplica & $0, \infty 0$ \\
\hline Prado Ferreina & Magistério & Magistéria & $2.455,35$ & Näa se aplica & Nāa se aplica & $0, \infty 0$ \\
\hline Sertanópolis & Magistério & Pedagogia & $2.345,00$ & Magistério & Pedagogia & $1.100,00$ \\
\hline Tamarana & Pedagagia & Pedagogia & $2.455,35$ & Magistério & Magistério & $2.455,35$ \\
\hline
\end{tabular}

Fonte: Questionário eletrônico da Jurisdição do NRE de Londrina. 
Em Londrina, desde o concurso de 2001, é necessário comprovar Ensino Superior para lecionar na EI, informação contida no edital do concurso. A deliberação que vale para todas as ofertas, tanto públicas quanto privadas, sob nº02/16, aponta

Art.50. O professor para atuar na Educação Infantil deverá ter a formação em nível superior, em curso de licenciatura em Pedagogia ou Normal Superior de graduação plena, em instituições de ensino superior, sendo admitida como formação mínima a oferecida em nível médio, na modalidade Normal (LONDRINA, 2016).

Como não há indicativo único na exigência da formação docente, fica condicionada à possibilidade ou ao interesse do gestor da rede privada a exigência para a contratação, já que a lei prevê que o Magistério seja condição ingressante. Em Londrina, na negociação salarial dos CEIs, participam três instituições: 1 Sindicato dos Professores das Escolas Particulares de Londrina e Norte do Paraná (SINPRO); 2 Sindicato das Entidades Culturais, Recreativas, de Assistência Social, de Orientação e Formação Profissional do Paraná (SECRASO) representando os trabalhadores; 3 Prefeitura Municipal (PM) representando as mantenedoras e a Secretaria de Educação.

Em relação ao salário, apenas seis cidades declararam valores iniciais dos professores do CMEI e do CEI, sendo que os demais se abstiveram de responder, ao mencionar "não se aplica". Os declarantes foram: Bela Vista do Paraíso e Cambé, trouxeram um valor aproximado de ambos; Centenário de Sul e Tamarana indicaram o mesmo valor; Londrina e Sertanópolis indicaram disparidade indicando valor superior para o CMEI. O valor menor de CMEI foi declarado por Centenário do Sul, e o maior em Londrina. No CEI, o menor ficou com Bela Vista do Paraíso, e o maior em Tamarana. A disparidade é grande, considerando que o salário do professor pode ser um indício de qualidade na oferta.

Esta disparidade salarial entre pública e privada faz com que haja um "mal-estar" entre professores dos CMEIs e CEIs, já que o trabalho é o mesmo, porém, a exigência expressa acima, é condição para ingresso na rede pública, deixando muito acirrada a busca por uma vaga pública quando há concurso, que estão cada vez mais escassos. Esse é um indicativo de suma importância no que tange à qualidade do ensino. Sobre isso, Saviani (2013, p. 221), corrobora com nosso estudo, ao enfatizar que há 
Precariedade na infraestrutura e nos equipamentos das escolas, na formação de professores, nas condições de exercício docente, nos baixos salários; em suma, na desídia das autoridades em assumir, na prática, a prioridade conferida à educação no texto da Constituição, nas leis complementares, assim como no discurso que se tornou hegemônico entre os políticos, empresários e em todos os setores que compõem a sociedade. $\mathrm{Na}$ verdade, este discurso valorizador da educação convive, contraditoriamente, com uma visão que enfraquece o papel do Estado em benefício dos mecanismos de mercado negando, na prática, o enunciado constitucional da educação como direito de todos e dever do Estado.

Tudo isso, entre outras questões, faz com que a carreira docente seja pouco atrativa para os jovens, que optam por outras carreiras mais valorizadas. No montante geral, nos gráficos abaixo, estão organizadas as porcentagens de atendimento em CEI e CMEI do somatório da Região e o de Londrina, e, ainda, por corte etário - creche e pré-escola. Retrata também a somatória do atendimento em CMEI e CEI de ambos, com o intento de tornar visível a presente oferta em sua totalidade.

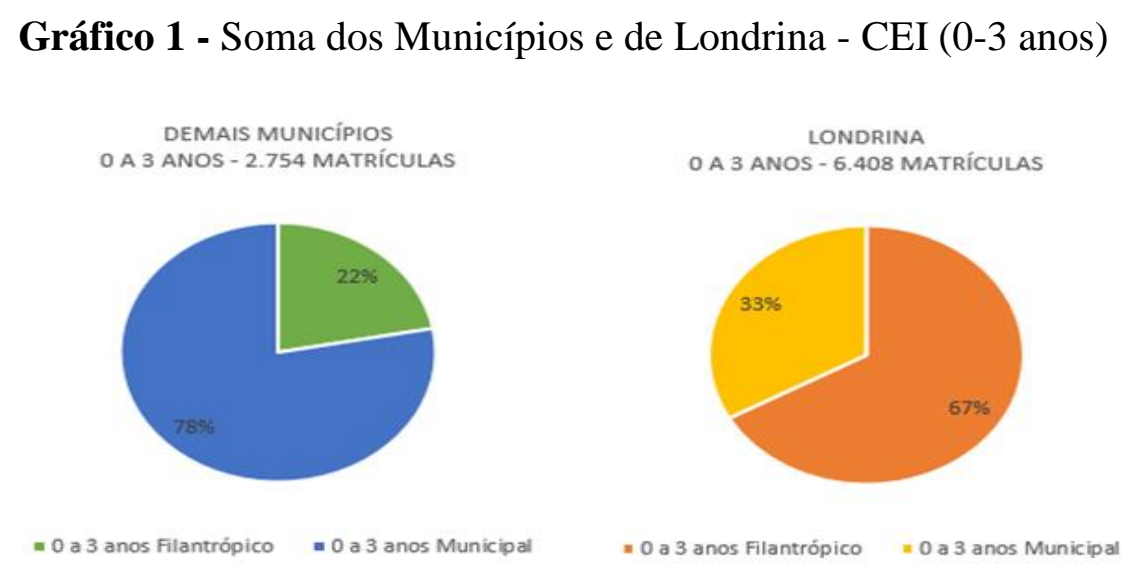

Fonte: Questionário eletrônico da Jurisdição do NRE de Londrina. Elaborado pelas autoras.

Gráfico 2 - Soma dos Municípios e de Londrina -CMEI (4 e 5 anos)

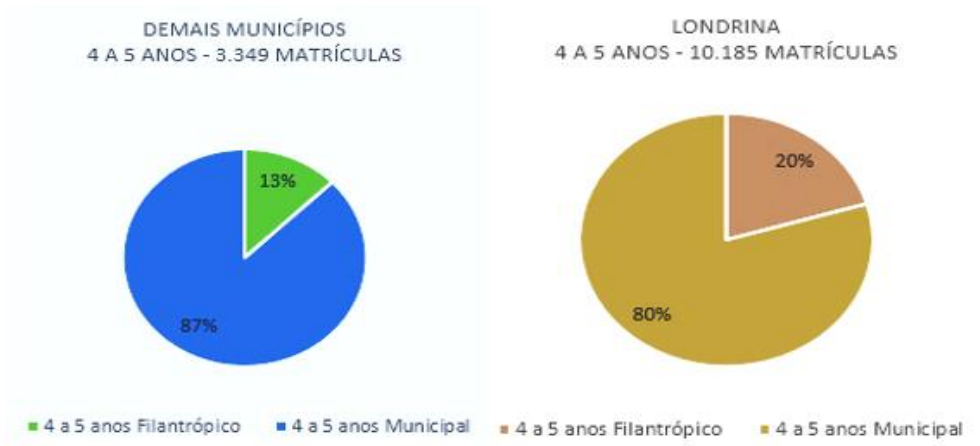

Fonte: Questionário eletrônico da Jurisdição do NRE de Londrina. Elaborado pelas autoras. 
Os gráficos apresentam que, na somatória por faixa etária de 0-3 anos, há superioridade no atendimento filantrópico, e, por sua vez, de 4 e 5 anos, o atendimento é muito superior no público municipal. Isso pode ser justificado pelo FUNDEB que determinou o prazo de 2016 para que os municípios assumissem a pré-escola e assim houve uma corrida por parte das prefeituras para não perder esse prazo, já que isso seria revertido em prejuízo na captação de recursos para a educação.

Dessa forma, as creches ultrapassam o atendimento em CEIs em relação aos CMEIs, e a distância entre creche e pré-escola continua sendo ampliada, mantendo a preferência municipal pela oferta da pré-escola.

Outro dado importante foi a respeito da falta de vagas, chamada de demanda reprimida, revelou que na marcha histórica por vagas de EI, em comparação com décadas anteriores, o quadro apresenta avanços na oferta, sem, contudo, sanar a demanda.

Gráfico 3 - Demanda manifesta por vaga dos municípios

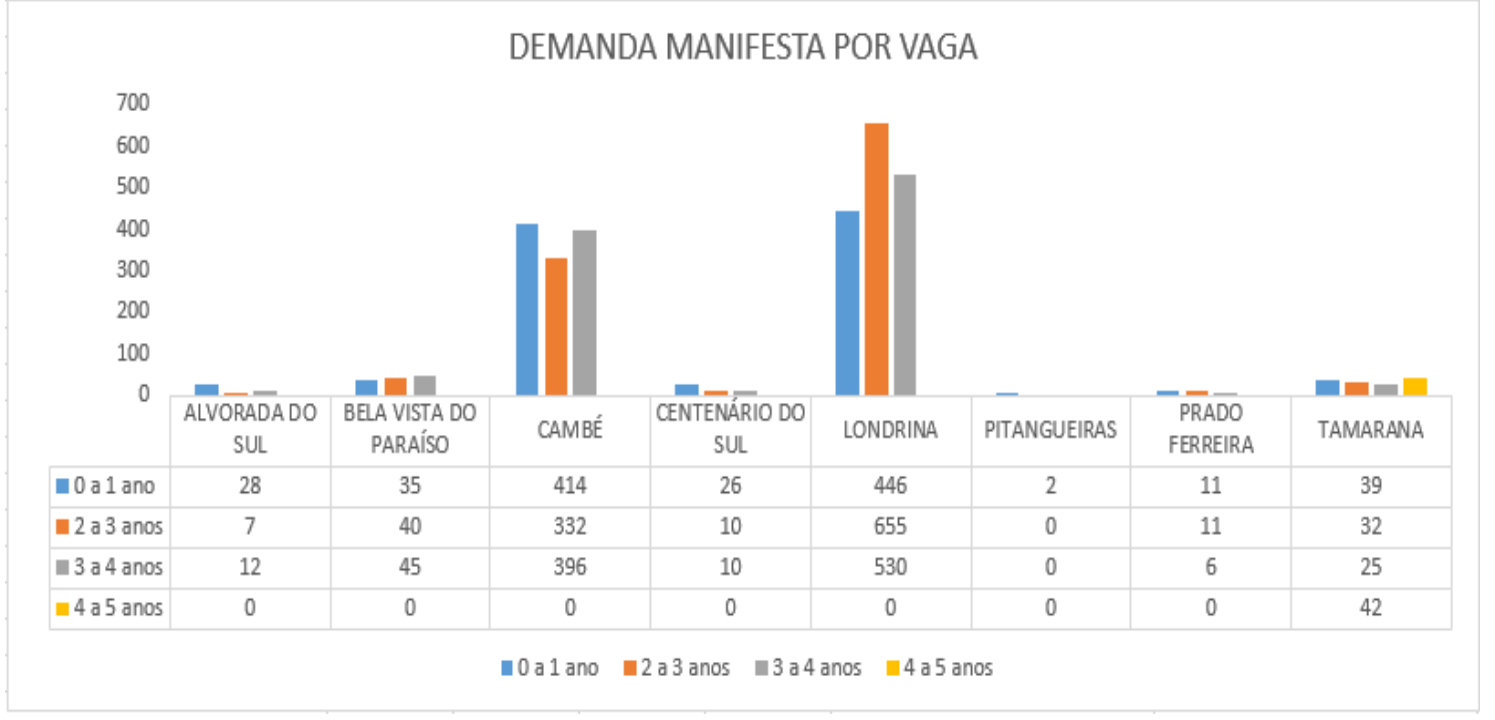

Fonte: Questionário eletrônico da Jurisdição do NRE de Londrina. Elaborado pelas autoras.

Observamos que apenas Tamarana mencionou falta de vagas à pré-escola. O gráfico apresenta que em Londrina e Cambé existe uma longa fila de espera por vagas da creche, contudo, ressaltamos que Londrina conseguiu triplicar o atendimento público nos últimos anos, todavia, a filantropia tem uma parcela muito importante de atendimento.

Em Londrina, uma medida tomada pela prefeitura para zerar a fila de espera de 4 e 5 anos foi a parcialidade do turno de atendimento. Todas as crianças da pré-escola passaram a ser atendidas em meio período (início em 2017) dobrando o número de atendimento desse corte 
etário, sendo que o atendimento em jornada parcial deve ser, no mínimo, de quatro horas diárias e o de período integral igual ou superior a sete horas diárias, ambas em período diurno, regulado e supervisionado por órgão competente do sistema de ensino (LONDRINA, 2016).

Averiguamos que a demanda manifesta por vaga reprimida concentra-se na creche, já que para a pré-escola houve praticamente a universalização do acesso (com exceção de Tamarana que declarou ausência de 42 vagas para esta etapa). A maior concentração fica em Londrina, tanto em matrícula quanto em demanda reprimida de vagas, o que é justificável, pois é um município de grande porte, e os demais, com exceção de Cambé, são de pequeno porte.

Tendo em vista os fatos e princípios apontados, o processo em que a Política Educacional se concretiza demanda uma visão da conjuntura de totalidade, na qual o Terceiro setor possui importante atuação. As consequências desse tipo de atendimento são graves no entorno do ideal da democratização da EI, que vê a prorrogação se perpetuar nos Planos de Educação e nos Planos de Governo.

Elencamos alguns pontos, diante da investigação realizada, que aclamam avanços para a EI, como: Concretização em espaços institucionais e coletivos, não-domésticos, de origem pública ou privada, e submetidos a fiscalização de origem pública; direito de vinculações de recursos financeiros do FUNDEB; práticas de educação que concebe a criança enquanto sujeito de direitos, com ensino fundamentado em práticas de cuidar e educar - indissociáveis; a exigência de trabalho desenvolvidos por professores habilitados; ampliação significativa em instituições públicas - CMEIS na Jurisdição do NRE de Londrina.

Finalmente, a investigação traz um último dado que clarifica e responde à questão inicial que motivou esta pesquisa, a de saber se o atendimento da Educação Infantil está concentrado no setor público ou privado filantrópico ao numerar quantidade de unidades de EI filantrópicas e municipais dos 19 municípios que compõem a Jurisdição do NRE de Londrina. Seguem os dados: 
Tabela 2 - Número de CMEI e CEI dos 19 municípios NRE de Londrina

\begin{tabular}{|c|c|c|c|}
\hline \multirow{2}{*}{ MUNICÍPIOS } & CMEI & CEI & \multirow{2}{*}{$\begin{array}{c}\text { Função do Responsável pelo } \\
\text { Preenchimento }\end{array}$} \\
\hline & Quantidade & Quantidade & \\
\hline 1ALVORADA DO SUL & 5 & 0 & Assessora Pedagógica \\
\hline 2 BELA VISTA PARAÍSO & 1 & 2 & Dirigente Municipal da Educação \\
\hline 3 CAFEARA & 1 & 0 & Técnico Administrativo \\
\hline 4 CAMBÉ & 24 & 1 & Secretária de Educação \\
\hline 5 CENTENÁRIO DO SUL & 2 & 3 & Diretora Pedagógica \\
\hline 6 FLORESTÓPOLIS & 5 & 0 & Secretária de Gerência \\
\hline 7 GUARACI & 2 & 0 & Secretário de Educação \\
\hline 8 IBIPORÃ & 17 & 0 & Consulta Escolas - Paraná Digital. \\
\hline 9 JAGUAPITÃ & 3 & 1 & Documentadora Escolar \\
\hline 10 LUPIANÓPOLIS & 3 & 0 & Consulta Escolas- Paraná Digital. \\
\hline 11 LONDRINA & 34 & 53 & Apoio Pedagógico \\
\hline 12 MIRASELVA & 1 & 0 & Coordenação Pedagógica \\
\hline 13 PITANGUEIRAS & 1 & 0 & Secretária de Educação \\
\hline 14 PORECATU & 3 & 0 & $\begin{array}{c}\text { Assessora Pedagógica da Educação } \\
\text { Infantil }\end{array}$ \\
\hline 15 PRADO FERREIRA & 2 & 0 & Secretário de Educação \\
\hline 16 PRIMEIRO DE MAIO & 4 & 0 & $\begin{array}{c}\text { Coordenadora Pedagógica Educação } \\
\text { Infantil }\end{array}$ \\
\hline 17 ROLÂNDIA & 9 & 4 & $\begin{array}{l}\text { Gerente Documentação } \\
\text { Escolar Municipal }\end{array}$ \\
\hline 18 SERTANÓPOLIS & 1 & 2 & Coordenação Pedagógica \\
\hline 19 TAMARANA & 1 & 1 & Assessora Pedagógica \\
\hline TOTAL & 119 & 67 & \\
\hline
\end{tabular}

Fonte: Questionário eletrônico da Jurisdição do NRE de Londrina/ Consulta Escolas - Paraná Digital. Elaborado pela autora.

Ao analisar tais dados, o que causou surpresa e certo contentamento foi a comprovação de avanços de atendimento municipal à EI em toda a Jurisdição. Os esforços efetuados em prol de garantir atendimento via CMEI neste recorte geográfico têm sido traduzidos em ampliação de garantia do direito da criança à Educação.

Em síntese, observamos que o atendimento da Educação Infantil deste recorte geográfico aponta para avanço na municipalização, sendo que onze municípios, dos dezenove pesquisados, já atingiram a municipalização. No entanto, isso não equivale a dizer que tenham garantido a universalização, pois ainda há muita criança sem a conquista desse direito, 
principalmente nas cidades de Londrina e Cambé, onde a procura é muito superior frente aos pequenos municípios.

\section{Considerações finais}

O direito à educação pública, gratuita e de qualidade seria um trampolim para a efetivação do direito da criança, já que a aprendizagem neste nível escolar é de grande importância para o desenvolvimento do ser humano, na constituição de sua personalidade, em sua cognição, linguagem e relações com o meio físico e natural, bem como nas relações socioafetivas que constrói.

Destacamos, que sua garantia ainda não se efetivou devido à dotação orçamentária, pois, segundo o governo, a EI gera altos custos para implementação e atendimento público, o que tem justificado as PPPs em muitos municípios.

A conquista do Direito da Criança a uma Educação pública e de qualidade dos 0 aos 5 anos de idade ainda é elemento de luta política da sociedade organizada, no sentido de exigir do Estado sua oferta, manutenção e permanência. Se faz necessária a conquista de condições de trabalho dignas para os professores de EI, salários justos a estes, juntamente com outras ações com vistas a efetivar a democratização e a universalização da EI na sociedade brasileira.

Pudera que a prática de nossa Jurisdição do NRE de Londrina, como indicou o resultado desta pesquisa, numa marcha crescente para a municipalização, seja buscada como meta de universalização, não somente neste recorte geográfico, mas em todo o território nacional, na superação das PPPs. Assim, será efetivado o que consta na LDBEN 9394/96, que garante a todas as crianças que assim desejarem o direito de uma educação pública, gratuita e de qualidade na Educação Infantil, compreendendo também a creche e não somente a pré-escola.

Por certo que nossa responsabilidade aumenta quando sabemos da importância desta fase do desenvolvimento das crianças, sendo assim, que nossas ações possam somar forças diante dos desafios que se apresentam, sejam de mercado, meritocracia, carreira docente, financiamento, enfim, da gama que se revela quando o que está em questão é a efetivação da garantia dos direitos da criança. Começando pelo acesso, podemos avançar para a qualidade e, finalmente, para o alcance de uma educação pública, gratuita e de qualidade para a Educação Infantil. 


\section{Referências}

ADRIÃO, Theresa. (Coord.) Estratégias municipais para a oferta da Educação Básica: as parcerias público-privadas. Relatório de pesquisa: Fapesp. 2009.

BOBBIO, Norberto. A era dos direitos. Tradução Nelson Coutinho, apresentação de Celso Lafer. Nova ed. $7^{\text {a }}$ reimpressão, Rio de Janeiro: Elsevier, 2004.

BRASIL. Lei de Diretrizes e Bases da Educação Nacional. Lei n ${ }^{\circ}$ 9.394, de 20 de dezembro de 1996. Cadernos de Educação: CNTE. Brasília, 1999.

BRASIL. Constituição Federal da República do Brasil. 05/10/1988. Brasília: Senado Federal, 2000.

BRASIL. Congresso Nacional. Emenda Constitucional nº 59, de 11 de novembro de 2009. Diário Oficial [da] República Federativa do Brasil, Brasília, 12 nov. 2009.

BRASIL. Lei no 13.005, de junho de 2014. Aprova o Plano Nacional de Educação - PNE e dá outras providências. Brasília: MEC, jun. 2014.

BRASIL. Lei $n^{\circ} 13.348$, de 10 de outubro de 2016a. Altera a Lei $n^{\circ} 11.494$, de 20 de junho de 2007, que Regulamenta o Fundo de Manutenção e Desenvolvimento da Educação Básica e de Valorização dos Profissionais da Educação - FUNDEB e dá outras providências. Diário Oficial [da] República Federativa do Brasil, Brasília, DF, 2016. Disponível em: http://www.planalto.gov.br/ccivil_03/_ato2015-2018/2016/lei/113348.htm. Acesso em: $12 / 10 / 2018$

BRASIL. Emenda Constitucional $n^{\circ} 95$ de 2016b. Altera o Ato das Disposições Transitórias, para instituir o novo regime fiscal, e dá outras providências. Disponível em: http://www2.camara.leg.br/legin/fed/emecon/2016/emendaconstitucional-95-15-dezembro2016-784029-publicacaooriginal-151558-pl.html. Acesso em 28/10/2018.

CURY, Carlos Roberto Jamil. A educação infantil como direito. In: MEC. Subsídio para credenciamento e funcionamento de instituição infantil. Vol. II, Brasília, 1998, p. 09-16.

KUHLMANN JR M. Educando a infância brasileira. LOPES, E.M.T. FARIA FILHO, L.M.; VEIGA, C.G. (ORGS). 500 anos de Educação no Brasil. Belo Horizonte. Autêntica, 2001.

LONDRINA. Normas e Princípios para a Educação Infantil no Sistema Municipal de Ensino de Londrina. Deliberação n ${ }^{\circ}$ 3158, 13 de dezembro de 2016a.Londrina: CMEL, 2016.

Disponível em:

http://www.londrina.pr.gov.br/dados/images/stories/Storage/cons_educacao/cmel/deliberacao/ deliberacao_n\%20003_2016_normas_educacao_infantil_smel_cmel.pdf. Acesso em 12/10/2018.

MARCILIO, M.C. A roda dos expostos e a criança abandonada na História do Brasil. 17261950. In: FREITAS, M.C. (org.) História Social da Infância no Brasil. São Paulo: Cortez, 1997. 
MERISSE, A. et. al. Lugares da infância: reflexões sobre a história da criança na fábrica, creche e orfanato. São Paulo: Arte \& Ciência, 1997.

OLIVEIRA, D. A. Educação Básica: gestão do trabalho e da pobreza. Petrópolis, RJ: Vozes, 2010.

ROSEMBERG, Fúlvia. Do embate para o debate: educação e assistência no campo da educação infantil. MACHADO, Maria Lucia A. (Org.). Encontros e Desencontros em educação infantil. São Paulo: Cortez, 2002. p. 63-78.

SARMENTO, Manuel Jacinto. Para uma agenda da educação da infância em tempo integral assente nos direitos da criança. In: ARAÚJO (Org.). Educação Infantil em jornada de tempo integral: dilemas e perspectivas. MEC, EDUFES, Vitória, ES, 2015.

SAVIANI, Demerval. A educação na Constituição Federal de 1988, avanços no texto e sua neutralização no contexto de 25 anos de vigência. RBPAE, v. 29, nº 2, p. 207-221, maio/ago. 2013.

UNESCO. Conferência De Joimtien. Declaração Mundial sobre educação para todos. 1990. 